\title{
Health-Seeking Behavior of Dengue Hemorrhagic Fever Patients in Several Hospitals in Bandung West Java Indonesia
}

\author{
Ressa Novita Afandi, ${ }^{1}$ Bachti Alisjahbana, ${ }^{2}$ Ardini S. Raksanagara ${ }^{3}$ \\ ${ }^{1}$ Faculty of Medicine Universitas Padjadjaran Bandung, Indonesia, ${ }^{2}$ Department of Internal \\ Medicine, Faculty of Medicine Universitas Padjadjaran/Dr. Hasan Sadikin General Hospital \\ Bandung, Indonesia, ${ }^{3}$ Department of Public Health Faculty of Medicine Universitas Padjadjaran, \\ Bandung, Indonesia
}

\begin{abstract}
Background: Dengue hemorrhagic fever is one of the major global public health problems. Secondary prevention of dengue fever must be conducted to prevent high mortality rate by giving appropriate diagnosis and early management. This study was conducted to identify health-seeking behavior in dengue hemorrhagic patients and its related factors.

Methods: This study involved 98 dengue hemorrhagic patients from four hospitals in Bandung region during July until November 2014. The hospitals were 2 public hospitals and 2 private hospitals. A questionnaire and in depth interview were used to collect the data.

Results: Among 98 patients, 54 patients (55\%) sought a right medical treatment timely, whereas 44 patients (45\%) delayed. The first seeking behaviour to treat the disease was using over-the-counter drugs, followed by visiting a private clinic doctor. The second choice to seek health care was going to a private clinic doctor and hospital.
\end{abstract}

Conclusions: Health-seeking behavior in dengue hemorrhagic patients in Bandung is inappropriate which can cause delay in treatment.

Keywords: Health-seeking behavior, dengue hemorrhagic fever, dengue hemorrhagic fever patients

\section{Introduction}

In 2009, the World Health Organization reported that there were 50.000 .000 cases of dengue infection every year around the world and about five hundred thousand cases required hospitalization. The percentage of mortality cases was $2.5 \%$ of the total cases in the world. Indonesia has the highest number of dengue cases and mortality in South East Asia. ${ }^{1}$ A report by WHO stated that 25.000 out of 150.000 cases in Indonesia occurred in Jakarta and West Java. Fatal case was 1\% of the total cases. ${ }^{1} \mathrm{~A}$ previous study reported that incidence rate of dengue fever in West Java in 2005 is 18 cases per $1000 .^{2}$

Delayed diagnosis and handling are factors causing the dengue fever become severe and unhelped., ${ }^{3,4}$ Rapid diagnosis and handling rely on the availability of health care service facilities and on the awareness of each individual in seeking health care. Each individual plays an important role in managing ones health, including the responsiveness to seek health care service for diagnosing and treating the diseases. A study about human treatment behaviour in Africa showed that the first aid for treating malaria was using overthe-counter (OTC) drugs and herbs which were not prescribed by a doctor. This study also reported that mortality is induced by poor access to health care service and severity of the disease. ${ }^{5}$ False understanding of the disease, which was considered as a self-limiting disease, was the cause of this phenomenon. ${ }^{4}$

Prognosis of dengue fever depends on responsiveness to the treatment and the clinical manifestation. The slower response in handling the disease, the worse prognosis and clinical manifestation of the disease are. ${ }^{6}$ Secondary prevention of the dengue fever is aimed to prevent death. One of the secondary preventions of dengue is by rapid diagnosis and handling. Every individual should understand the golden period for treating the disease. This study was conducted to describe the health seeking behaviour of dengue fever patients. 


\section{Methods}

This study used a descriptive quantitative design and was conducted at four hospitals in Bandung between July-November 2014. The hospitals were Ujungberung District Hospital, Al-Ihsan District Hospital, Bina Sehat Hospital, and AMC Hospital. Subjects of the study were patients with dengue fever. Patients with dengue fever were determined by using the diagnostic criterion of WHO. Positive for three of four criteria are needed to prove as dengue fever. The criteria are fever 2-7 days, leucopenia $<5000 \mathrm{cell} / \mathrm{mm}^{3}$, thromobocytopenia $<150.000$ cell $/ \mathrm{mm}^{3}$, and a positive immunoglobulin test. ${ }^{1,8}$ The exclusion criteria were, a patient who has other working diagnosis (e.g. typhoid fever) and who filled the quesionnaire incompletely. The data were collected by direct interview using a questionnaire. The permission for data collection was approved by the involving hospitals before the study was conducted and also the permission from the selected patients were obtained by signing an informed consent form. This study obtained ethical clearance from the Ethical Committee of Dr. Hasan Sadikin General Hospital Bandung. Data collection was obtained by purposive random sampling. A minimum sample was determined using the descriptive category formula $(\mathrm{d}=0.1)$. The minimum sample was 97 subjects. ${ }^{7}$ The data were processed using Microsoft Excel and SPSS for Windows and the results were shown by tables.

The results were divided into 2 groups. The first group was for favorable behavior and the second group was for unfavorable behavior. Favorable behavior was used for subjects who did the treatment for maximum 3 days, therefore the subjects measured at maximum on day 4 th of admission were favorable. ${ }^{1}$

Furthermore, Lawrence W. Green explained that the 3 factors which influence the behaviour are Predisposing factor (Knowledge and Attitude), Enabling Factor (Access), and Reinforcing Factor (Economy and Education). ${ }^{9}$ Score of knowledge was collected from the total score of answers of the subject in the questionnaire. Score of Attitude was collected from the total score of answers of the subject in the quesionnaire, then measured by the Likert Scale. Score of Aspect was collected from the total score of answers of the subject in the quesionnaire measured, then by Thurstone Scale. Access was measured by calculating the distance between home and hospital, cost for transportation and every difficulty in reaching the hospital. Economic status was measured by the monthly salary. Out of the 100 subjects

\section{Table 1 Distribution of Respondent Characteristics}

\begin{tabular}{lcc}
\hline \multicolumn{1}{c}{ Respondent Characteristics } & Total (n=98) & Percentage (\%) \\
\hline Age Group & 30 & 31 \\
$<11$ years & 16 & 16 \\
11-20 years & 15 & 15 \\
$21-30$ years & 18 & 18 \\
$31-40$ years & 9 & 9 \\
$41-50$ years & 10 & 10 \\
$>50$ years & & 43 \\
Sex & 42 & 57 \\
Male & 56 & 100 \\
Female & & 100 \\
Diagnosis Criteria & 98 & 100 \\
Fever $2-7$ days & 98 & 12 \\
Leucopenia $\leq 5000$ cell/mm3 & 98 & \\
Trombocytopenia $<150.000$ sel/mm3 & $12 / 12$ & \\
IgG dan IgM / tested & & \\
Duration of Fever before Hospital Admission & & \\
Median (range) & days (2-7 days) \\
\hline
\end{tabular}


Table 2 Health-Seeking Pattern

\begin{tabular}{lccccc}
\hline \multirow{2}{*}{ Health-Seeking } & \multicolumn{5}{c}{ Sequence } \\
\cline { 2 - 5 } \multicolumn{1}{c}{ st } & 2nd & 3rd & 4 th & 5 th \\
\hline Over-the-Counter (OTC) Drugs & $47(48 \%)$ & $5(5 \%)$ & $0(0 \%)$ & $0(0 \%)$ & $0(0 \%)$ \\
Traditional/Herbal & $3(3 \%)$ & $4(4 \%)$ & $2(2 \%)$ & $5(5 \%)$ & $1(1 \%)$ \\
Midwife & $4(4 \%)$ & $2(2 \%)$ & $0(0 \%)$ & $0(0 \%)$ & $0(0 \%)$ \\
Small Primary Health Centre & $1(1 \%)$ & $0(0 \%)$ & $0(0 \%)$ & $0(0 \%)$ & $0(0 \%)$ \\
Main Primary Health Centre & $7(7 \%)$ & $6(6 \%)$ & $2(2 \%)$ & $0(0 \%)$ & $0(0 \%)$ \\
Private Clinic Doctor & $27(28 \%)$ & $37(38 \%)$ & $10(10 \%)$ & $1(1 \%)$ & $0(0 \%)$ \\
Private Practice Doctor & $7(7 \%)$ & $12(12 \%)$ & $4(4 \%)$ & $0(0 \%)$ & $0(0 \%)$ \\
Hospital & $2(2 \%)$ & $31(32 \%)$ & $54(55 \%)$ & $20(20 \%)$ & $1(1 \%)$ \\
Cumulative inpatient & $1(1 \%)$ & $27(28 \%)$ & $77(79 \%)$ & $97(99 \%)$ & $98(100 \%)$ \\
\hline
\end{tabular}

interviewed, 98 subjects were included in the study and 2 subjects were excluded because they were diagnosed with typhoid.

\section{Results}

Of the 98 inpatients who were enrolled in the study, female was more dominant than men with a median age of 22 years (range 1 year to 80 years). All patients showed symptoms, signs and findings resembling dengue fever. The group undergoing early treatment consisted of $59(60 \%)$ people and late treatment was 39 people $(40 \%)$. From the 98 patients interviewed, only 12 patients got the immunoglobulin test.
Dengue fever health-seeking behavior can be seen from the way of treatment and response time to treatment of the respondents. Most respondents were using over-the-counter drugs on the first treatment and others chose going to a private clinic doctor. While, on the second treatment, respondents chose visiting a doctor at a private clinic or hospital (Table 2).

Some respondents still used herbal remedies or traditional medicine, despite being hospitalized. The cumulative result was the number of respondents who were admitted to hospital with the highest jump in the third treatment. Theorder of treatment of respondents was found in Figure.

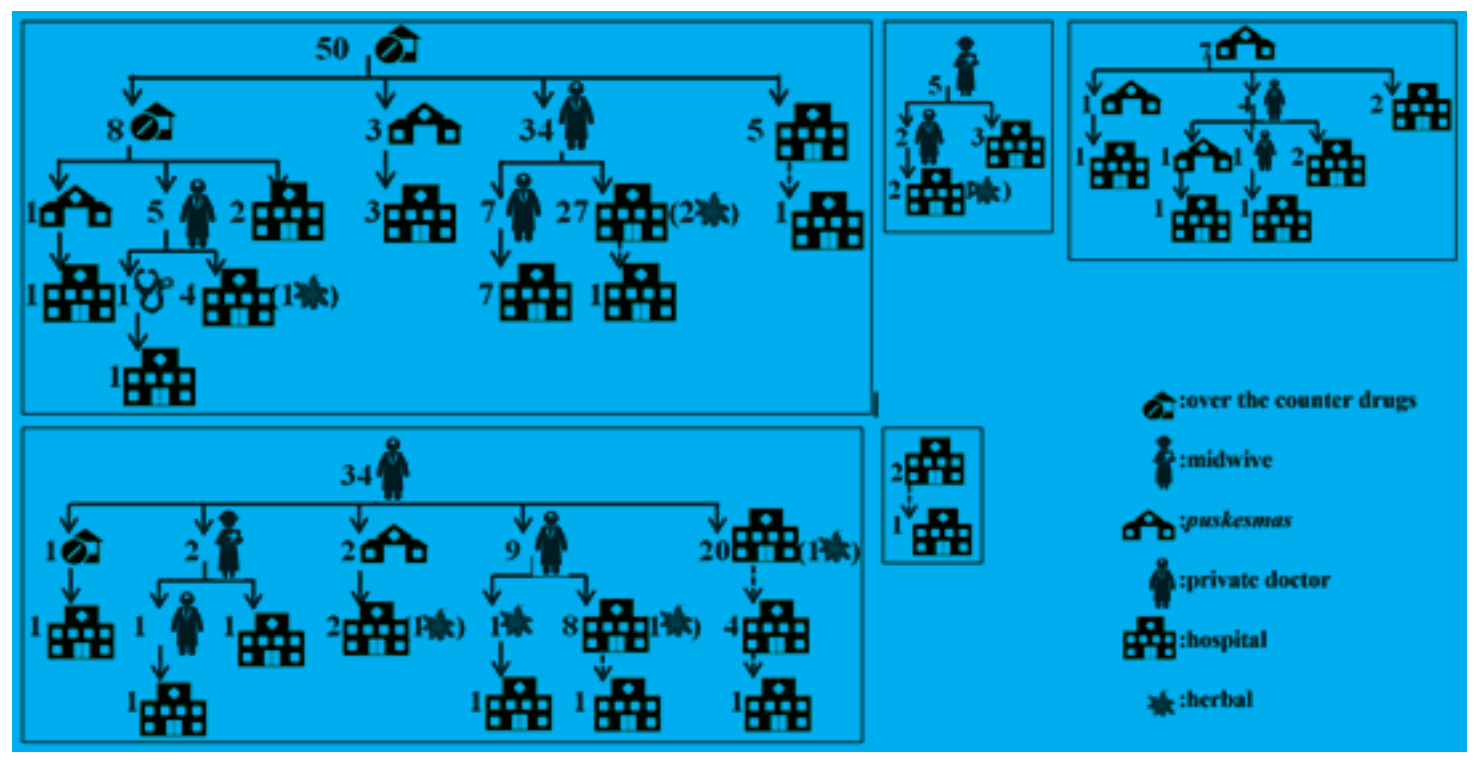

Figure Health-Seeking Pattern

Althea Medical Journal. 2018;5(3) 
Table 2 Health-Seeking Pattern

\begin{tabular}{|c|c|c|c|}
\hline \multirow{2}{*}{ Variable } & \multicolumn{3}{|c|}{ Total Respondent (\%) } \\
\hline & Favorable $(n=54)$ & Unfavorable $(n=44)$ & Total $(n=98)$ \\
\hline \multicolumn{4}{|l|}{ Predisposing Factor } \\
\hline \multicolumn{4}{|l|}{ Knowledge } \\
\hline Good & $24(44 \%)$ & $18(41 \%)$ & $42(43 \%)$ \\
\hline Enough & $26(48 \%)$ & $20(45 \%)$ & $46(47 \%)$ \\
\hline Poor & $4(8 \%)$ & $6(14 \%)$ & $10(10 \%)$ \\
\hline \multicolumn{4}{|l|}{ Attitude } \\
\hline Good & $16(29 \%)$ & $10(23 \%)$ & $26(27 \%)$ \\
\hline Enough & $36(67 \%)$ & $33(75 \%)$ & $69(70 \%)$ \\
\hline Poor & $2(4 \%)$ & $1(2 \%)$ & $3(3 \%)$ \\
\hline \multicolumn{4}{|l|}{ Enabling Factor } \\
\hline \multicolumn{4}{|l|}{ Access } \\
\hline Good & $21(39 \%)$ & $11(25 \%)$ & $32(33 \%)$ \\
\hline Enough & $30(55 \%)$ & $26(59 \%)$ & $56(57 \%)$ \\
\hline Poor & $3(6 \%)$ & $7(16 \%)$ & $10(10 \%)$ \\
\hline \multicolumn{4}{|l|}{ Reinforcing Factor } \\
\hline \multicolumn{4}{|l|}{ Income } \\
\hline More than minimum wage & $32(59 \%)$ & $24(55 \%)$ & $56(57 \%)$ \\
\hline Less than minimum wage & $21(39 \%)$ & $19(43 \%)$ & $40(41 \%)$ \\
\hline Very Less than minimum wage & $1(2 \%)$ & $1(2 \%)$ & $2(2 \%)$ \\
\hline \multicolumn{4}{|l|}{ Education } \\
\hline Undergraduate from Elementary & $16(30 \%)$ & $18(41 \%)$ & $34(35 \%)$ \\
\hline Elementary & $4(7 \%)$ & $9(20 \%)$ & $13(13 \%)$ \\
\hline Junior High School & $8(15 \%)$ & $3(7 \%)$ & $11(11 \%)$ \\
\hline Senior High School & $20(37 \%)$ & $14(32 \%)$ & $34(35 \%)$ \\
\hline University & $6(11 \%)$ & $0(0 \%)$ & $6(6 \%)$ \\
\hline
\end{tabular}

In the group of respondents who did the first treatment using over the counter drugs/ traditional medicine, 22 of them were late. While in the group who went to a paramedic/ midwife/health center and clinic the first time, three people were late in each group. In the group who went to the private doctor the first time, eleven people were late.

Of all respondents, 18 of them had bad step treatment. Out of the eighteen people, eight people were treated twice using different overthe-counter drugs/traditional medicine, four people came to the hospital more than once due to lack of bed, two people came to primary health care three times, and four people took own medication after visiting a primary health care. Of the 18 patients, only five people had early treatment.
The predisposing factors were obtained from the knowledge and attitudes of respondents values (Table 3). Most of the respondents answered the questions correctly. However, many respondents did not know the name of dengue fever mosquito intermediaries. Less than $30 \%$ of respondents had a good attitude. Overview supporting factors would be obtained from the description of aspects of the respondent's access. Reinforcing factors were obtained from the economic and educational background of the respondents. Most respondents (57\%) had a salary above the minimum wage of West Java. In 2014, the minimum wage of West Java was $R p 1,700,000.00$. While the value of very less than the minimum wage was revenue less than USD 300,000.00. Regarding education, 
most respondents (35\%) did not graduate from elementary and high school.

\section{Discussions}

Out of the 98 respondents, 54 have a favourable practice, 26 late seeking treatments, 18 were unfavourble as 5 people did not show good step approach, and 13 were late and did not show good approach. The respondents who took unfavourable path for treatment seeking, problems might occur due to two things: the patient or the primary health care. It can be seen in the results of studies which showed, the most delays are caused by the negligence of a doctor who did a blood test on the third day of fever. Most treatment of the patients who do not have a good step is also caused by doctors who do not perform good education to the patients. However, some other problems are caused by the patients themselves.

In this study, the first treatment most widely performed was the use of over the counter drugs, and visit to a private clinic doctor. These results are similar to previous studies in Cambodia ${ }^{4}$ which stated that the majority of Cambodia's population in some regions choose to buy drugs at the drug store, use herbal remedies, and go to a private surgeon as the first treatment.

In the group of patients treated with the over-the-counter drugs/traditional remedies at first time, 26 people had an unfavorable behavior and 9 of them had bad step. Eight patients underwent treatment with the overthe-counter drugs/traditional remedies twice because the first drug taken did not have effect and were recommendations from other people to change treatment. Of the eight people, six people were late. One patient did a bad step treatment because the hospital was full on the first admission, so the blood test was performed on the next day. This delay could be caused by many respondents thought that the fever was a common fever as in the previous study. ${ }^{10}$

Three out of five respondents went to a paramedic/midwife late at the hospital. While from respondents who went to the clinic first, three people were late and two of them did a bad step treatment. Respondents went to the primary health care three times. The best blood test was on the second visit or no longer than the third day so that delays could be prevented.

In the group of respondents who went to the private doctor first, 13 were classified as unfavorable and 7 of them were bad step.
Three of the four respondents who treated themselves after all overdue health care, were late. Distrust of the patient and patient's errors obstructed the detection of dengue fever. Three respondents came to the hospital more than once due to lack of bed at the hospital. One of them came first on the third day and was not checked, and the otherst were not treated because the hospital was crowded.

The occurring problems lead to many delays and bad step treatments among health care workers who are less prepared, clinics and hospitals that do not have a blood test facility and unavailability of beds. These weaknesses are the biggest factors which cause the patient who go to hospital late for definitive treatment.

The level of knowledge wasbetter of respondents who performed favorable compared to the unfavorable. This is consistent with previous studies that claimed positive results in knowledge and health education. ${ }^{11}$ The educational background also affects the knowledge background of the respondent. The picture showed the attitudeof the majority of respondents answered already quite well. However, there were some respondents who considered dengue fever was not a contagious infection because they had a person to person transmission. Some respondents only knew that dengue fever was caused by mosquitoes and was not contagious. While those who knew that dengue fever is an infectious disease, did not hesitate to reply that dengue fever is considered an infectious disease. Based on a previous study, this behavior differs from the selection of the treatment in question in a population that does not have dengue fever. ${ }^{12}$ A study in Kudat ${ }^{13}$ reported, most respondents choose to go to the hospital as a major option. It shows that behavior is not only dependent on the predisposing factors but also on the supporting and reinforcing factors.

Access is important in determining the action of the respondents. As previous studies stated that the affordability of a treatment has an effect on behavior; this study also showed the same result. ${ }^{4}$ Respondents who had access due to the short distance, low cost, and easiness to go to hospital, were more quickly in response to cases of dengue fever. On the other hand, respondents who due to the long distance, high cost, and difficulties getting to hospital were many in the poor groups. Respondents who received a good treatment behavior had an income above the minimum wage which was more than those who received bad treatment. The number of respondents whose income was far below the minimum 
wage was also less than those who received bad treatment. This is consistent with studies in Africa which stated that the lower the income, the higher the level of morbidity. ${ }^{14}$ However, this study did not show the significancy.

Behavior patterns of dengue fever treatment in hospitals in Bandung area were drawn from the manner and time of treatment. For treatments, over-the-counter drugs and doctor's private clinic were the first treatment options that were most and reached the highest leap of hospital admission on the fourth day. Existing factors influencing behavior were knowledge, attitudes, access, economic, and past education. These factors thought did not have differences between the good and the bad.

This study has several limitations. The researcher can only obtain the data of hospitalized patients in class II and III with an excuse not to disrupt the service. With these limitations, patients are less diverse, especially on the economic status. Economic factors, education, and knowledge classify similarly. In addition, this study is biased since it only examined the inpatients and did not examine the outpatients.

This study concludes that health seekingbehavior in patients with dengue hemorrhagic patients is inappropriate which can cause the delay of treatment, and the patient's options before going to hospital are time-consuming.

In order to discover $t$ most influential factor further research is needed. With the data of this study, health workers are expected to increase knowledge about dengue treatment protocols for the appropriate time to diagnose. Moreover, the knowledge of society should be improved further by education, both counseling in society and counseling conducted by primary care physicians. In addition, the government is expected to improve the infrastructure and programs with the objective to optimize facilities for accessing health services. Thus, increasing the capacity of early detection of dengue fever with systematic referral patterns, early and good ladder treatment can be accomplished.

\section{References}

1. WHO Regional Office for South-East Asia. Comprehensive guidelines for prevention and control of dengue and dengue haemorrhagic fever. New Delhi:WHO;2011.

2. Porter KR, Beckett CG, Kosasih H, Tan RI, Alisjahbana B, Rudiman PIF, et al.
Epidemiology of dengue and dengue hemorrhagic fever in a cohort of adults living in Bandung, West Java, Indonesia. Am J Trop Med Hyg. 2005;72(1):60-6.

3. Guha-Sapir D, Schimmer B. Dengue fever: new paradigms for a changing epidemiology. Emerg Themes Epidemiol. 2005;2(1):1-10.

4. Khun S, Manderson L. Health seeking and access to care for children with suspected dengue in Cambodia: an ethnographic study. BMC Public Health. 2007;7(1):262.

5. Müller 0 , Traoré $\mathrm{C}$, Becher $\mathrm{H}$, Kouyaté B. Malaria morbidity, treatment-seeking behaviour, and mortality in a cohort of young children in rural Burkina Faso. Trop Med In Health. 2003;8(4):290-6.

6. Tanner L, Schreiber M, Low JG, Ong A, Tolfvenstam T, Lai YL, et al. Decision tree algorithms predict the diagnosis and outcome of dengue fever in the early phase of illness. PLoS neglected tropical diseases. 2008;2(3):e196.

7. Dahlan MS. Besar sampel dan cara pengambilan sampel dalam penelitian kedokteran dan kesehatan. Jakarta: Salemba Medika; 2009.

8. Shah I, Katira B. Clinical and laboratory profile of dengue, leptospirosis and malaria in children: a study from Mumbai. Arch Dis Child. 2007;92(6):561.

9. Notoatmodjo PDS. Promosi Kesehatan Teori dan Aplikasi. Jakarta: Rineka Cipta; 2005.

10. Kamat VR. "I thought it was only ordinary fever!" cultural knowledge and the micropolitics of therapy seeking for childhood febrile illness in Tanzania. Soc Sci Med. 2006;62(12):2945-59.

11. Kenkel DS. Health behavior, health knowledge, and schooling. J Polit Econ. 1991:287-305.

12. Onwujekwe O, Chukwuogo 0 , Ezeoke U, Uzochukwu B, Eze S. Asking people directly about preferred health-seeking behaviour yields invalid response: an experiment in south-east Nigeria. J Public Health. 2011;33(1):93-100.

13. WN R, Masturoh I, Hendri J, Ipa M. Gambaran Perilaku Pencarian Pengobatan Penderita Demam Berdarah Dengue di Kabupaten Ciamis Propinsi Jawa Barat. Aspirator: Jurnal Penelitian Penyakit Tular Vektor. 2010;2(2).

14. Cisse B, Luchini S, Moatti JP. Progressivity and horizontal equity in health care finance and delivery: What about Africa?. Health Policy. 2007;80(1):51-68. 